\title{
A case of acute Sheehan's syndrome and literature review: a rare but life-threatening complication of postpartum hemorrhage
}

Shinya Matsuzaki* D, Masayuki Endo, Yutaka Ueda, Kazuya Mimura, Aiko Kakigano, Tomomi Egawa-Takata, Keiichi Kumasawa, Kiyoshi Yoshino and Tadashi Kimura

\begin{abstract}
Background: Sheehan's syndrome occurs because of severe postpartum hemorrhage causing ischemic pituitary necrosis. Sheehan's syndrome is a well-known condition that is generally diagnosed several years postpartum. However, acute Sheehan's syndrome is rare, and clinicians have little exposure to it. It can be life-threatening. There have been no reviews of acute Sheehan's syndrome and no reports of successful pregnancies after acute Sheehan's syndrome. We present such a case, and to understand this rare condition, we have reviewed and discussed the literature pertaining to it. An electronic search for acute Sheehan's syndrome in the literature from January 1990 and May 2014 was performed.

Case presentation: A 27-year-old woman had massive postpartum hemorrhage (approximately $5000 \mathrm{~mL}$ ) at her first delivery due to atonic bleeding. She was transfused and treated with uterine embolization, which successfully stopped the bleeding. The postpartum period was uncomplicated through day 7 following the hemorrhage. However, on day 8 , the patient had sudden onset of seizures and subsequently became comatose. Laboratory results revealed hypothyroidism, hypoglycemia, hypoprolactinemia, and adrenal insufficiency. Thus, the patient was diagnosed with acute Sheehan's syndrome. Following treatment with thyroxine and hydrocortisone, her condition improved, and she was discharged on day 24.

Her next pregnancy was established 2 years after her first delivery. She required induction of ovulation for the next conception. The pregnancy, delivery, and postpartum period were uneventful. An electronic search of the literature yielded 21 cases of acute Sheehan's syndrome. Presenting signs varied, including adrenal insufficiency (12 cases), diabetes insipidus (4 cases), hypothyroidism (2 cases), and panhypopituitarism (3 cases), with a median time of presentation after delivery for each of those conditions being 7.9, 4, 18, and 9 days, respectively. Serial changes in magnetic resonance imaging were reported in some cases of acute Sheehan's syndrome.
\end{abstract}

Conclusion: Clinicians should be aware of the risk of acute Sheehan's syndrome after a massive postpartum hemorrhage in order to diagnose it accurately and treat it promptly.

Keywords: Hyponatremia, Hypopituitarism, Postpartum hemorrhage, Sheehan syndrome, Sheehan's syndrome, Subsequent pregnancy

\footnotetext{
* Correspondence: zacky@gyne.med.osaka-u.ac.jp

Department of Obstetrics and Gynecology, Osaka University Graduate School

of Medicine, 2-2 Yamadaoka, Suita, Osaka 565-0871, Japan
} 


\section{Background}

Postpartum hemorrhage $(\mathrm{PPH})$ is an obstetric emergency that occurs in $1-2 \%$ of live births [1]. Sheehan's syndrome is well known as a complication of $\mathrm{PPH}$; this condition can present with chronic symptoms after a relatively long latent period, including failure to lactate, mild headache, fatigue, nausea, and amenorrhea [2]. Although the frequency of Sheehan's syndrome has decreased because of recent advances in obstetrical care, Sheehan's syndrome is one of the most important causes of hypopituitarism [3]. Sheehan's syndrome is generally diagnosed several years postpartum; therefore, it has been recognized as a chronic condition. However, in some cases, Sheehan's syndrome presents with acute symptoms and this variant may be life threatening [3]. Here we report our experience with a case of this rare type of Sheehan's syndrome and present a literature review of this condition.

\section{Case presentation}

A 27-year-old woman (gravida 1, para 0) delivered a healthy $2715-\mathrm{g}$ female infant at 40 weeks of gestation in a private hospital. The patient had no notable medical or family history and had not experienced problems during the course of her pregnancy. She developed a massive hemorrhage at the time of delivery and transferred to our hospital for emergency treatment. The estimated total blood loss was approximately $4000 \mathrm{~mL}$ on admission.

On admission to our hospital, the patient had a blood pressure of 110/50 $\mathrm{mmHg}$ and a heart rate of 140 beats/ min. A complete blood count $(\mathrm{CBC})$ revealed a hematocrit (HCT) level of $11.4 \%$ and a hemoglobin $(\mathrm{Hb})$ level of $4.1 \mathrm{~g} / \mathrm{dL}$. We immediately started transfusion and uterotonic therapies and employed uterine embolization, which successfully stopped the bleeding. We estimated her total blood loss to be approximately $5000 \mathrm{~mL}$ at this point, and she received $3500 \mathrm{~mL}$ of fluid infusions, including $2800 \mathrm{~mL}$ of red blood cells, $1200 \mathrm{~mL}$ of fresh frozen plasma, and $400 \mathrm{~mL}$ of platelets by transfusion. Subsequently, her CBC recovered (HCT: 27.6\% and $\mathrm{Hb}: 9.6 \mathrm{~g} / \mathrm{dL}$ ) and vital signs stabilized (blood pressure: $140 / 90 \mathrm{mmHg}$ and heart rate: 100 beats/min).

On day 7 postpartum, the patient's general condition was relatively stable, with no evidence of hypotension, general fatigue, headache, failure to lactate, or hypoglycemia; therefore, we planned to discharge her on the following day. However, on day 8, the patient experienced a grand mal seizure and became comatose. Because her oxygen saturation level decreased to $60 \%$, she was sedated and intubated. The laboratory data showed slightly low $\mathrm{Hb}$ (10.3 g/ dL) and HCT levels (29.7\%), a normal platelet count $\left(262 \times 10^{3} / \mu \mathrm{L}\right)$, and low sodium $\left(\mathrm{Na}^{+}, 111 \mathrm{mEq} / \mathrm{L}\right)$ and chloride $\left(\mathrm{Cl}^{-}, 84 \mathrm{mEq} / \mathrm{L}\right)$ levels. Other tests were within the normal range. Magnetic resonance imaging (MRI) of the pituitary gland revealed no abnormalities and intracranial hemorrhage could be ruled out. Consequently, we diagnosed that her seizure was caused by hyponatremia and started the appropriate $\mathrm{NaCl}$ replacement treatment to increase her $\mathrm{Na}^{+}$levels by $10 \mathrm{mEq} /$ day.

The patient's hormone levels on postpartum day 8 are shown in Table 1a. These results suggested that the pituitary dysfunction was either due to Sheehan's syndrome or lymphocytic hypophysitis. The adrenal insufficiency was treated with hydrocortisone. A second MRI scan did not reveal lymphocytic hypophysitis, and a Gadolinium-enhanced T1-weighted MRI showed a normal pituitary gland on postpartum day 15 (7 days after the seizure; Fig. 1a). On day 17, after the seizure, we performed hormone stimulation tests for corticotropin-releasing hormone $(\mathrm{CRH})$, luteinizing hormone-releasing hormone (LH-RH), and thyrotropinreleasing hormone (TRH) and on day 18, we performed a stimulation test for growth hormone-releasing peptide (GH-RP). The hormone levels in Table 1b demonstrated low reactivity for $\mathrm{ACTH}, \mathrm{TSH}, \mathrm{FSH}$, prolactin (PRL), and growth hormone $(\mathrm{GH})$. Based on these results, we diagnosed the patient with acute Sheehan's syndrome. Following treatment with thyroxine and hydrocortisone, her condition improved.

We discharged the patient on day 24 postpartum and advised her to continue the hydrocortisone $15 \mathrm{mg} /$ day and thyroxine sodium $75 \mathrm{mg} /$ day treatment. At 6 months postpartum, the follow-up CRH-, LH-RH-, and TRHstimulation tests revealed persistent pituitary dysfunction (Table 1b), and we diagnosed her with generalized hypopituitarism. A repeat MRI at this point also revealed an atrophic pituitary gland (Fig. 1b) without clinical evidence of neurological impairment. At 12 months postpartum, she developed a pituitary amenorrhea that necessitated estrogen and progesterone hormone treatment. Her next pregnancy was established after two years of her first delivery using ovulation-inducing hormones and human menopausal gonadotropin-human chorionic gonadotropin (hMG-hCG) treatment. During her pregnancy, she was maintained on hydrocortisone $15 \mathrm{mg} /$ day and thyroxine sodium $75 \mathrm{mg} /$ day. Fetal growth was determined to be appropriate for gestational age, and no major anomalies were observed on ultrasound at 19, 28, 32, 36, and 40 weeks of gestation. At 41 weeks of gestation, she required labor induction and delivered a healthy 2870-g female infant with Apgar scores of 8 and 9 at 1 and $5 \mathrm{~min}$, respectively. A total amount of $100 \mathrm{mg}$ of hydrocortisone was added as a steroid cover at the time of delivery. There were no complications postpartum and she was discharged 5 days postpartum. At 12 months after her second delivery, amenorrhea was also observed and necessitated repeat estrogen and progesterone hormone treatment. 
Table 1 (a) The results of hormone levels at the day of seizure. The pituitary dysfunction was observed. (b) The results of $\mathrm{CRH}$, TRH, $\mathrm{LH}-\mathrm{RH}$, and GH-RP stimulation test. Low reactivity for ACTH, TSH, FSH, prolactin (PRL), and growth hormone (GH) was observed

\begin{tabular}{|c|c|c|c|c|c|c|c|}
\hline \multicolumn{8}{|l|}{ a } \\
\hline \multirow[t]{2}{*}{ The day after seizure } & & \multicolumn{6}{|l|}{ Day 0} \\
\hline & normal range & & & & & & \\
\hline $\begin{array}{l}\text { adrenocorticotropic hormone } \\
\text { (ACTH) }\end{array}$ & $0-60 \mathrm{pg} / \mathrm{mL}$ & \multicolumn{6}{|l|}{14} \\
\hline cortisol & $4.3-20 \mu \mathrm{g} / \mathrm{dl}$ & \multicolumn{6}{|l|}{3.4} \\
\hline $\begin{array}{l}\text { thyroid-stimulating hormone } \\
\text { (TSH) }\end{array}$ & $0.400-4.80 \mathrm{MU} / \mathrm{mL}$ & \multicolumn{6}{|l|}{0.72} \\
\hline free thyroxine & $0.80-1.90 \mathrm{ng} / \mathrm{dL}$ & \multicolumn{6}{|l|}{0.9} \\
\hline PRL & $3.50-30.00$ ng/mL & \multicolumn{6}{|l|}{11.3} \\
\hline growth hormone $(\mathrm{GH})$ & $0.1-2.7 \mathrm{ng} / \mathrm{mL}$ & \multicolumn{6}{|l|}{0.18} \\
\hline \multicolumn{8}{|l|}{ b } \\
\hline The day after seizure & & \multicolumn{3}{|l|}{ Day 17} & \multicolumn{3}{|c|}{6 months } \\
\hline \multirow[t]{2}{*}{ duration after the stimulation } & & $0 \mathrm{~min}$ & $30 \mathrm{~min}$ & $60 \mathrm{~min}$ & $0 \mathrm{~min}$ & $30 \mathrm{~min}$ & $60 \mathrm{~min}$ \\
\hline & normal range & none & CRH stimulation & CRH stimulation & none & CRH stimulation & CRH stimulation \\
\hline \multirow{2}{*}{$\begin{array}{l}\text { adrenocorticotropic hormone } \\
\text { (ACTH) }\end{array}$} & $0-60 \mathrm{pg} / \mathrm{mL}$ & 9 & 19 & 18 & $<5.0$ & 12 & 20 \\
\hline & & none & TRH stiumulation & TRH stiumulation & none & TRH stiumulation & TRH stiumulation \\
\hline \multirow{2}{*}{$\begin{array}{l}\text { thyroid-stimulating hormone } \\
\text { (TSH) }\end{array}$} & $0.400-4.80 \mathrm{MU} / \mathrm{mL}$ & 0.69 & 4.32 & 2.98 & 0.75 & 4.62 & 3.16 \\
\hline & & none & LH-RH stiumulation & LH-RH stiumulation & none & LH-RH stiumulation & LH-RH stiumulation \\
\hline FSH & $0.4-11 \mathrm{mlU} / \mathrm{ml}$ & 7.5 & 9.9 & 10.5 & 1.2 & 4.2 & 4.6 \\
\hline \multirow[t]{2}{*}{$\mathrm{LH}$} & $0.08-7.3 \mathrm{mlU} / \mathrm{mL}$ & 1.6 & 3.3 & 3.5 & 3.1 & 8.3 & 9.7 \\
\hline & & none & TRH stiumulation & TRH stiumulation & none & TRH stiumulation & TRH stiumulation \\
\hline \multirow[t]{2}{*}{ PRL } & $3.50-30.00$ ng/mL & 10.9 & 20.9 & 16.9 & 10 & 32.6 & 22.5 \\
\hline & & none & GH-RP stiumulation & GH-RP stiumulation & none & GH-RP stiumulation & GH-RP stiumulation \\
\hline growth hormone $(\mathrm{GH})$ & $0.1-2.7 \mathrm{ng} / \mathrm{mL}$ & 0.21 & 3.05 & 1.91 & 0.07 & 2.35 & 0.75 \\
\hline
\end{tabular}

Abbreviations: $A C T H$ adrenocorticotropic hormone, $C R H$ corticotropin-releasing hormone, $F S H$ follicle-stimulating hormone, $G H$ growth hormone, $G H-R P$ growth hormone releasing peptide, $L H$ - $R H$ luteinizing hormone-releasing hormone, $P R L$ prolactin; $T R H$ thyrotropin-releasing hormone, $T S H$, thyroid-stimulating hormone

\section{Discussion}

Sheehan's syndrome was first described by Sheehan in 1937 [4]; through improved management of hemodynamic complications, its incidence has gradually declined over time. Although the exact incidence is unknown and it rarely occurs in modern obstetric practices, Sheehan's syndrome still must be considered in cases of PPH. Sheehan's syndrome is pituitary necrosis after $\mathrm{PPH}$ and hypovolemia and occurs in 1-2\% of women who lose 1-2 L of blood with associated hypotension [5, 6]. Several studies have shown that the latent period between symptoms and postpartum hemorrhage can be several years in Sheehan's syndrome [2, 4, 7]. For example, in 1999, Banzal et al. reported significant delays between symptom onset and postpartum hemorrhage, with only two patients diagnosed within a year, 20 patients that were symptomatic for over 6 years before diagnosis, and appropriate treatment [7]. Symptoms that first occur within 6 weeks postpartum are defined as acute Sheehan's syndrome in this report because the postpartum period is commonly identified as 6 weeks after delivery.

Our case presented with a life-threatening seizure and coma as the first symptoms. Our literature review revealed that such marked and abrupt onset in Sheehan's syndrome are rare. The primary causes of postpartum seizures include eclampsia, cerebral ischemic changes, cerebral hemorrhage, cerebral venous sinus thrombosis, reversible cerebral vasoconstriction syndrome, epilepsy, and hypoglycemia [8]. None of the imaging results in our case revealed any brain disorders, and because the laboratory investigations revealed hyponatremia and following low hormonal levels, we reasonably concluded that our final diagnosis was acute Sheehan's syndrome with the loss of general pituitary function.

Only a few studies have discussed acute Sheehan's syndrome, and we found no literature review on this topic. Therefore, we performed a PubMed/Medline and Google Scholar search of the English literature between 


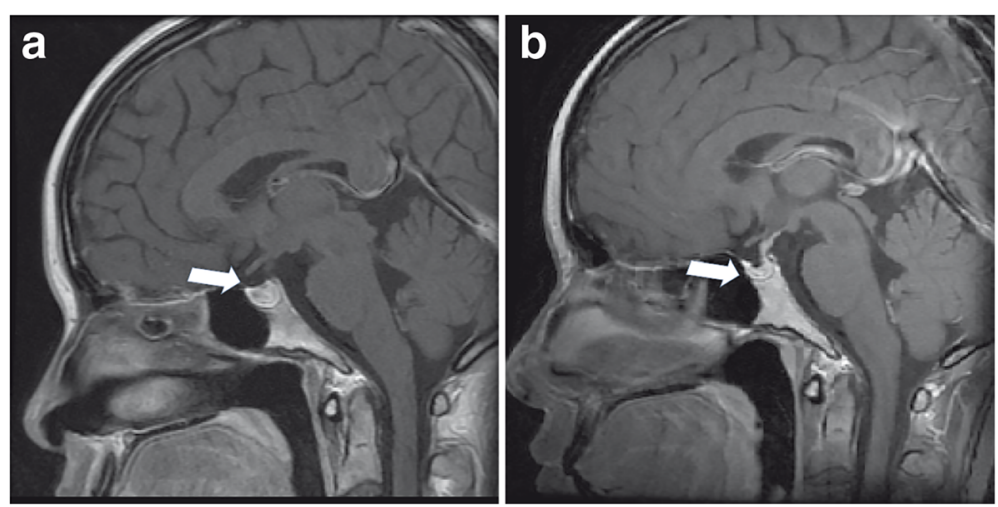

Fig. 1 Gadolinium-enhanced T1-weighted magnetic resonance image of the pituitary gland. a No change was observed in the pituitary gland on postpartum day 15 (day 7 after the seizure). b Marked diminution in the pituitary gland size was observed after 6 months. The white arrow indicates the pituitary gland

January 1990 and May 2014, using the key words "acute" or "early" and "Sheehan syndrome" or "Sheehan's syndrome." Searching with the keywords mentioned above, 52 articles were identified. We read these articles and selected those cases with patients whose symptoms first occurred within 6 weeks postpartum; this identified 19 suitable reports (21 cases including our case). Nineteen full texts of articles were read by the authors. Twenty cases of acute Sheehan's syndrome were published in international peer-reviewed literature. The 21 cases are summarized in Table 2 [9-27]. We selected the topics, which are distinct features of acute Sheehan's syndrome for further discussion.

Of the identified cases, 17 described the amount of postpartum bleeding. Most patients suffered a massive hemorrhage; however, in one case, a PPH of approximately $500 \mathrm{~mL}$ caused acute Sheehan's syndrome [23]. These results suggested that most cases of acute Sheehan's syndrome occurred after PPH, which is well known for traditional Sheehan's syndrome.

The $\mathrm{Hb}$ levels were mentioned in 12 cases, all of which experienced a moderate to severe decrease in $\mathrm{Hb}$ (approximately $3.0-8.8 \mathrm{~g} / \mathrm{dL}$ ). These results suggested that anemia is a reason for acute Sheehan's syndrome. However, some cases were not associated with either $\mathrm{PPH}$ or anemia.

It is difficult to discuss the relationship between hypotension and acute Sheehan's syndrome because the definition of shock was unclear in the previous reports. However, 12 of the 21 cases had experienced hypotension below $90 \mathrm{mmHg}$, which suggested that hypotension is a risk factor for acute Sheehan's syndrome. Dejager et al. reported an interesting case showing severe hypotension because of an epidural anesthesia causing acute Sheehan's syndrome; this study revealed that only hypotension may be cause the acute Sheehan's syndrome [13].
$\mathrm{PPH}$, anemia, and hypotension may decrease the blood flow to the pituitary and lead to necrosis of the gland. To prevent acute Sheehan's syndrome, the obstetrician should strive to prevent anemia and hypotension in the treatment of $\mathrm{PPH}$.

The first signs were reported within 3 days, 4-10 days, and 11-20 days postpartum in 6,10 , and 5 cases, respectively. Sixteen of 21 patients experienced the first signs within 10 days postpartum. Therefore, the obstetrician should be particularly vigilant for this condition during this time period. The first signs were hyponatremia because of adrenal insufficiency in 12 cases, diabetes insipidus in 4, hypothyroidism in 2 , and panhypopituitarism in 3. Notably, the length of time after delivery until the first sign was noted varied depending on the cause. Adrenal insufficiency presented at a median of 7.9 days (14 $\mathrm{h}-19$ days), diabetes insipidus at 4 days (1-7 days), hypothyroidism at 18 days (16-20 days), and panhypopituitarism at 9 days (4-17 days). Although the reasons for postpartum headache vary and may be difficult to diagnose accurately, acute Sheehan's syndrome is one possible cause. In our literature review, 6 of 21 patients reported severe headache on the day of delivery. There was no correlation between the presence of headache and the onset of signs indicating acute Sheehan's syndrome. The presence of severe headache on the day of delivery may indicate intracranial hemorrhage, but if that can be ruled out, the obstetrician should remain alert for the possible onset of acute Sheehan's syndrome.

MRI evidence of acute Sheehan's syndrome was reported in 13 cases. Early radiologic findings within postpartum day 20 were reported in 11 cases. In our case, the MRI findings were normal on postpartum day 15 (7 days after the seizure). Two studies reported that the MRI scans were normal on postpartum day 6; in addition, another study reported that normal scans were 


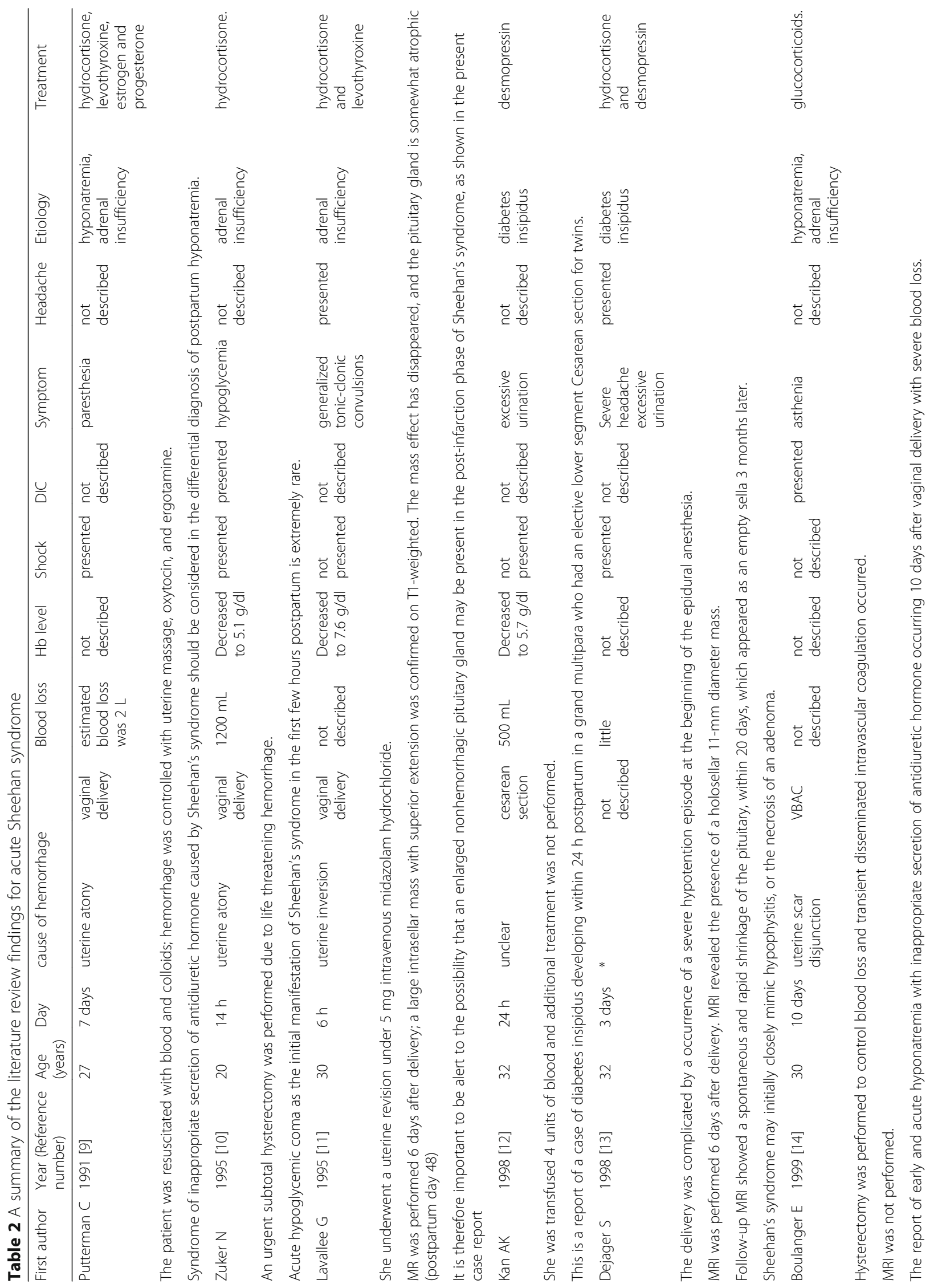




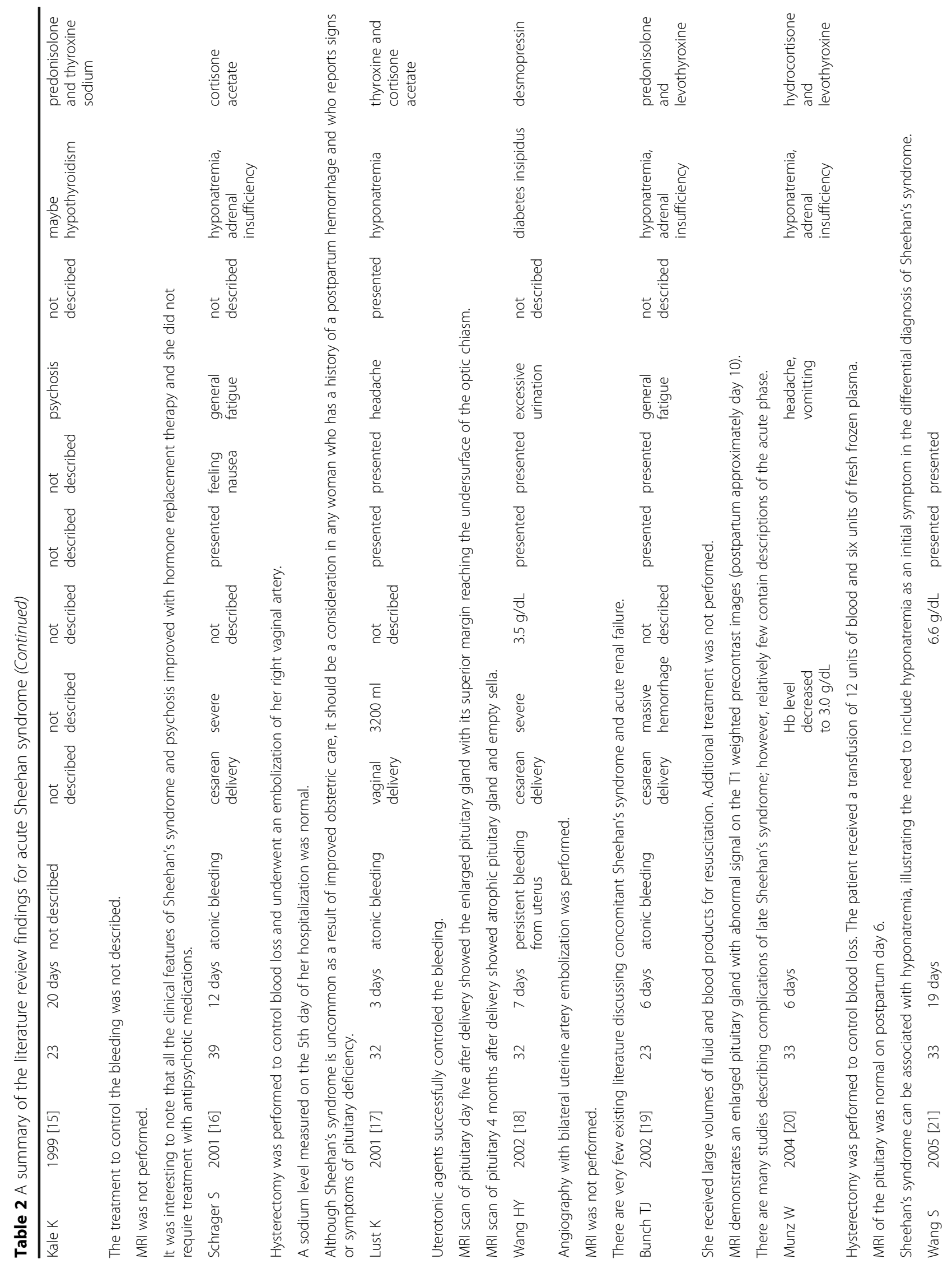




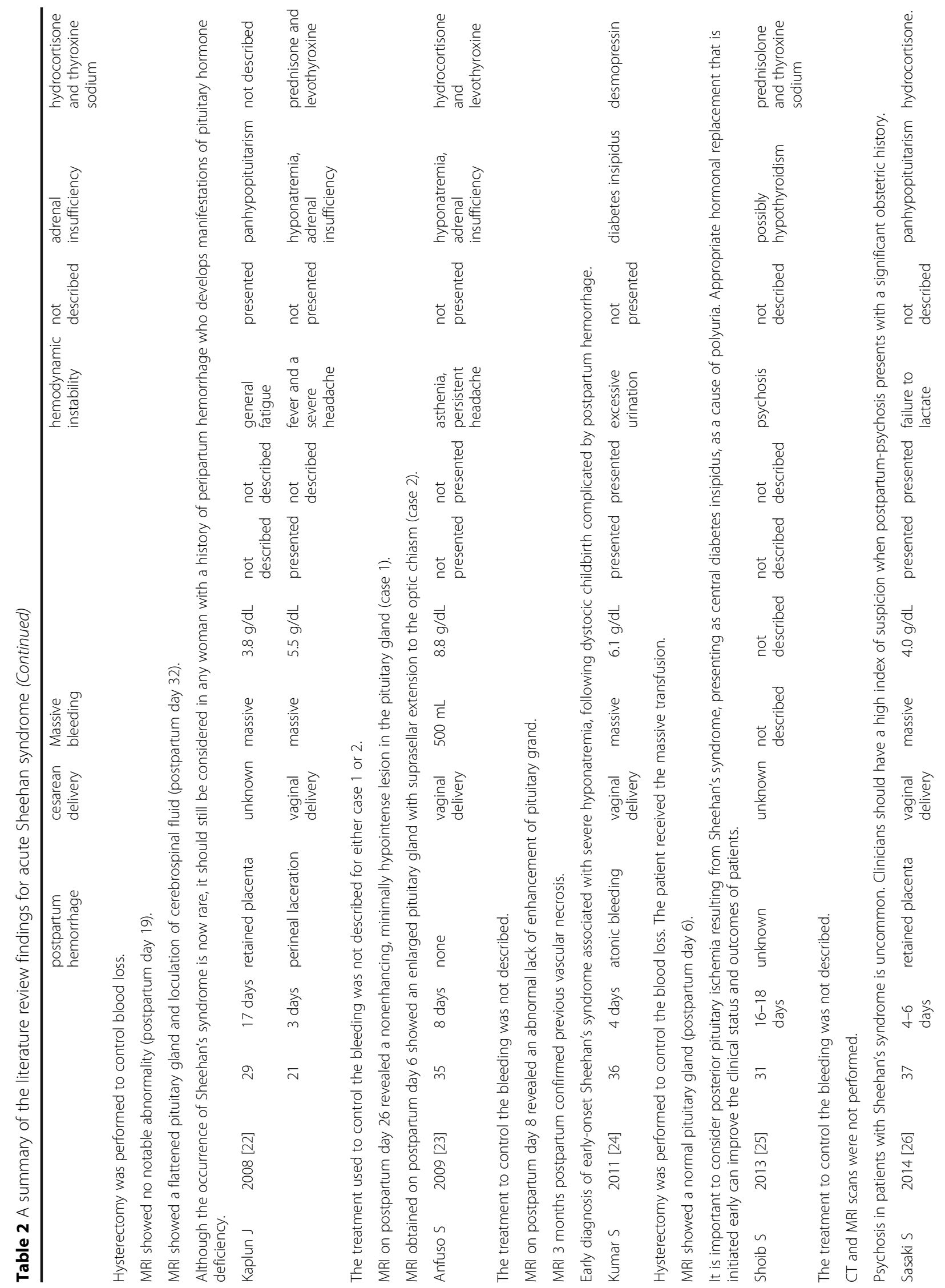




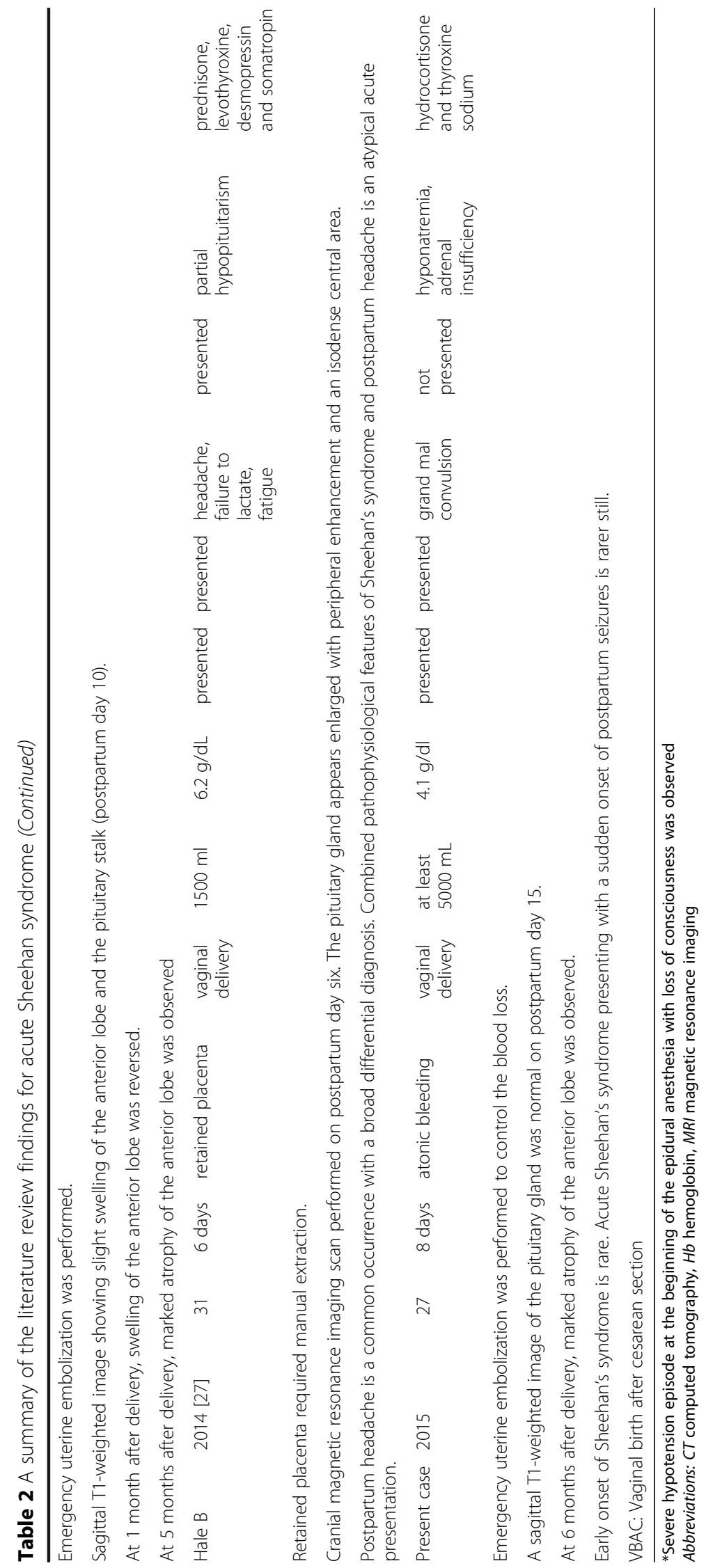


obtained on day 19 [20, 21, 24]. Seven studies reported their early MRI findings [11, 13, 17, 19, 22, 23, 26]. Lavallee et al. and Dejager et al. reported a large intrasellar mass with superior extension was confirmed on T1weighted on day $6[11,13]$. Bunch et al., Kaplun et al. and Sasaki et al. reported an enlarged pituitary gland with an abnormal signal on the T1-weighted precontrast images on postpartum day 10, day 10 and day 6 , respectively $[19,22,26]$. Anfuso et al. described MRI findings from postpartum day 8 that showed an abnormal lack of pituitary gland enhancement [23]. Although the data was limited, in four of eleven cases, there were insignificant findings because of acute Sheehan's syndrome on the MRI within postpartum 20 days. A large intrasellar mass with superior extension, an enlarged pituitary gland with an abnormal signal and an abnormal lack of pituitary gland enhancement were reported as early radiologic findings of acute Sheehan's syndrome.

Including our case, marked findings associated with Sheehan's syndrome have been observed at day 26, day 32, 3 months, 5 months, and 6 months [18, 22, 23, 26]. Specific findings included a non-enhancing, minimally hypointense lesion in the pituitary gland on day 26 postpartum [22] and a hypointense area with a flattened pituitary gland on day 32 postpartum [21]. An empty sella was observed several months postpartum [13, 22, 23, 26].

Pregnancy after acute Sheehan's syndrome has not been reported. Whether the patient needs an induction of ovulation or not depends on the severity of this condition. If the patient did not have menstrual cycles because of hypopituitarism, the patient may need an induction of ovulation to establish a pregnancy. Our patient had no menstrual cycles; therefore, the patient received hMG-hCG treatment and established a pregnancy.

A study of a large number of pregnancies in hypopituitarism has not been reported. The largest number of cases was reported by Kübler et al. who reviewed pregnancy management in women with hypopituitarism [28]. Based on the analysis of 31 pregnancies in 27 women, they concluded that women with hypopituitarism were at an increased risk of obstetrical complications; postpartum hemorrhage occurred in $8.7 \%$, transverse lie occurred in 16 , and $42.4 \%$ of the newborns who were small for gestational age. Fortunately, our patient had no obstetrical complications other than the postdate delivery.

The postdate delivery was probably not because of the loss of general pituitary function because a review reported no increase in the rate of postdate deliveries in women with hypopituitarism [28]. In addition, animal data has shown that the delivery proceeded normally in oxytocin-deficient mice [29]. However, because there have been few reported cases of pregnancy with generalized hypopituitarism, many such cases will be need to be studied to obtain more human data.

\section{Conclusion}

In summary, we report a rare case of Sheehan's syndrome in a woman with early symptoms of lifethreatening seizures, coma, and respiratory failure. After an initial resuscitation and treatment for PPH, the symptoms of Sheehan's syndrome significantly improved with appropriate hormone replacement treatment. Although healthcare providers should be aware of the possibility of Sheehan's syndrome that occurs several years postpartum complicated by $\mathrm{PPH}$, they should also consider the possibility of acute presentations of Sheehan's syndrome.

\section{Abbreviations \\ ACTH: Adrenocorticotropic hormone; $\mathrm{CRH}$ : Corticotropin-releasing hormone; FSH: Follicle-stimulating hormone; GH: Growth hormone; GH-RP: Growth hormone-releasing peptide; Hb: Hemoglobin; HCT: Hematocrit; LH- $\mathrm{RH}$ : Luteinizing hormone-releasing hormone; MRI: Magnetic resonance imaging; NaCl: Sodium chloride; PPH: Postpartum hemorrhage; PRL: Prolactin; $\mathrm{TRH}$ : Thyrotropin-releasing hormone; TSH: Thyroid-stimulating hormone}

\section{Acknowledgments}

The authors thank A. Yagi and K. Sakiyama for administrative assistance in preparation of this manuscript.

\section{Funding}

There is no source of financial support or funding.

\section{Availability of data and materials}

Not applicable.

\section{Authors' contributions}

SM, EM, TE, KY and KM made substantial contributions to conception and design, collected the clinical data and drafted as well as revised the manuscript. YU, AK and KK helped in drafting the manuscript and responded to the submission work. TK conceived and generally supervised of this study, and gave final approval of the version to be published. All authors read and approved the final manuscript.

\section{Competing interests}

All the authors declare that they have no financial or personal interference with other people or organizations that could inappropriately influence their work.

\section{Consent for publication}

Written informed consent was obtained from the patient for publication of this case report and any accompanying images. A copy of the written consent is available for review by the Editor of this journal.

\section{Ethics approval and consent to participate}

This study was approved by the Institutional Review Board and the Ethics Committee of the Osaka University Hospital (approval \#15240, approved on September 10, 2015).

\section{Publisher's Note}

Springer Nature remains neutral with regard to jurisdictional claims in published maps and institutional affiliations.

Received: 16 September 2015 Accepted: 9 June 2017 Published online: 14 June 2017

\section{References}

1. Gibbins KJ, Albright CM, Rouse DJ. Postpartum hemorrhage in the developed world: whither misoprostol? Am J Obstet Gynecol. 2013;208:181-3. 
2. Dokmetas HS, Kilicli F, Korkmaz S, Yonem O. Characteristic features of 20 patients with Sheehan's syndrome. Gynecol Endocrinol. 2006;22:279-83.

3. Kilicli F, Dokmetas HS, Acibucu F. Sheehan's syndrome. Gynecol Endocrinol. 2013;29:292-5.

4. Tessnow AH, Wilson JD. The changing face of Sheehan's syndrome. Am J Med Sci. 2010;340:402-6.

5. Vaphiades MS, Simmons D, Archer RL, Stringer W. Sheehan syndrome: a splinter of the mind. Surv Ophthalmol. 2003:48:230-3.

6. Kelestimur F. Sheehan's syndrome. Pituitary. 2003;6:181-8.

7. Banzal S, Ayoola EA. Sheehan's syndrome in Saudi Arabia. I Int J Gynaecol Obstet. 1999:66:181-2.

8. Edlow JA, Caplan LR, O'Brien K, Tibbles CD. Diagnosis of acute neurological emergencies in pregnant and post-partum women. Lancet Neurol. 2013;12: $175-85$.

9. Putterman C, Almog Y, Caraco Y, Gross DJ, Ben-Chetrit E. Inappropriate secretion of antidiuretic hormone in Sheehan's syndrome: a rare cause of postpartum hyponatremia. Am J Obstet Gynecol. 1991;165:1330-3.

10. Zuker N, Bissessor M, Korber M, Conrads M, Margolis J, Massel P, et al. Acute hypoglycaemic coma-a rare, potentially lethal form of early onset Sheehan syndrome. Aust N Z J Obstet Gynaecol. 1995;35:318-20.

11. Lavallee G, Morcos R, Palardy J, Aube M, Gilbert D. MR of nonhemorrhagic postpartum pituitary apoplexy. AJNR Am J Neuroradiol. 1995;16:1939-41.

12. Kan AK, Calligerous D. A case report of Sheehan syndrome presenting with diabetes insipidus. Aust N Z J Obstet Gynaecol. 1998;38:224-6.

13. Dejager S, Gerber S, Foubert L, Turpin G. Sheehan's syndrome: differential diagnosis in the acute phase. J Intern Med. 1998;244:261-6.

14. Boulanger E, Pagniez D, Roueff S, Binaut R, Valat AS, Provost N, et al. Sheehan syndrome presenting as early post-partum hyponatraemia. Nephrol Dial Transplant. 1999;14(11):2714-5.

15. Kale K, Nihalani N, Karnik N, Shah N. Postpartum psychosis in a case of sheehan's syndrome. Indian J Psychiatry. 1999:41(1):70-2.

16. Schrager S, Sabo L. Sheehan syndrome: a rare complication of postpartum hemorrhage. J Am Board Fam Pract. 2001;14:389-91.

17. Lust K, Mclntyre HD, Morton A. Sheehan's syndrome-acute presentation with hyponatraemia and headache. Aust N Z J Obstet Gynaecol. 2001;41: 348-51.

18. Wang HY, Chang CT, Wu MS. Postpartum hemorrhage complicated with irreversible renal failure and central diabetes insipidus. Ren Fail. 2002;24: 849-52.

19. Bunch TJ, Dunn WF, Basu A, Gosman RI. Hyponatremia and hypoglycemia in acute Sheehan's syndrome. Gynecol Endocrinol. 2002;16:419-23.

20. Munz W, Seufert R, Knapstein PG, Pollow K. Early postpartum hyponatremia in a patient with transient Sheehan's syndrome. Exp Clin Endocrinol Diabetes. 2004;112:278-80.

21. Wang SY, Hsu SR, Su SL, Tu ST. Sheehan's syndrome presenting with early postpartum congestive heart failure. J Chin Med Assoc. 2005;68:386-91.

22. Kaplun J, Fratila C, Ferenczi A, Yang WC, Lantos G, Fleckman AM, et al. Sequential pituitary MR imaging in Sheehan syndrome: report of 2 cases. AJNR Am J Neuroradiol. 2008;29:941-3.

23. Anfuso S, Patrelli TS, Soncini E, Chiodera P, Fadda GM, Nardelli GB. A case report of Sheehan's syndrome with acute onset, hyponatremia and severe anemia. Acta Biomed. 2009;80:73-6.

24. Kumar S, Burrows D, Dang S, Simmons D. Sheehan syndrome presenting as central diabetes insipidus: a rare presentation of an uncommon disorder Endocr Pract. 2011;17:108-14.

25. Shoib S, Dar MM, Arif T, Bashir H, Bhat MH, Ahmed J. Sheehan's syndrome presenting as psychosis: a rare clinical presentation. Med J Islam Repub Iran. 2013;27:35-7.

26. Sasaki S, Fujisawa I, Ishihara T, Tahara Y, Kazuma M, Fujiwara Y, et al. A novel hook-shaped enhancement on contrast-enhanced sagittal magnetic resonance image in acute Sheehan's syndrome: a case report. Endocr J. 2014;61:71-6.

27. Hale B, Habib AS. Sheehan syndrome: acute presentation with severe headache. Int J Obstet Anesth. 2014;23:383-6.

28. Kubler K, Klingmuller D, Gembruch U, Merz WM. High-risk pregnancy management in women with hypopituitarism. J Perinatol. 2009;29:89-95.

29. Nishimori K, Young $L$, Guo Q, Wang Z, Insel TR, Matzuk MM. Oxytocin is required for nursing but is not essential for parturition or reproductive behavior. Proc Natl Acad Sci U S A. 1996:93:11699-704.

\section{Submit your next manuscript to BioMed Central and we will help you at every step:}

- We accept pre-submission inquiries

- Our selector tool helps you to find the most relevant journal

- We provide round the clock customer support

- Convenient online submission

- Thorough peer review

- Inclusion in PubMed and all major indexing services

- Maximum visibility for your research

Submit your manuscript at www.biomedcentral.com/submit
Biomed Central 